\title{
Faculty Level Support of Graduate Attribute Assessment and Continuous Improvement Process
}

\author{
Aneta George and Liam Peyton \\ University of Ottawa, 800 King Edward, Ottawa, ON, Canada K1N 6N5 \\ atrai062@uottawa.ca, lpeyton@uottawa.ca
}

\begin{abstract}
We survey the approaches taken at several universities for faculty level support of graduate attribute assessment and continuous improvement process and present the approach taken at the University of Ottawa. Our approach consists of a common process for continuous improvement across programs, supported by templates for key tasks, and a common set of performance indicators for graduate attribute assessment supported by our Graduate Attribute Information Analysis system. We demonstrate our approach across three engineering programs (electrical engineering, computer engineering and software engineering) and report on specific issues encountered and results obtained.
\end{abstract}

Keywords: graduate attribute assessment, continuous improvement process, faculty performance indicators.

\section{INTRODUCTION}

The Graduate Attribute Information Analysis system (GAIA) [7] was developed at the University of Ottawa to support data collection and performance management of graduate attributes (GA) at the program level and at the course level. GAIA was initially developed and tested within the software engineering program (SEG). GAIA is now used by three engineering programs and supports a common faculty approach to data collection and reporting within a common continuous improvement process.

\subsection{Literature Review}

In 2009, Engineers Australia proposed a set of common performance indicators per criteria and advised that a "unified analysis either for all programs or groups of programs, will be appropriate because of a common operating environment" [5]. Reports on the Australian national project to create, identify, develop and implement "indicators and metrics across the Australian university sector" are provided by Chalmers [2].

In Canada, the Faculty of Engineering at University of Alberta developed a set of sub-attributes per each of the twelve CEAB graduate attributes. Most of these subattributes are common across all engineering programs and are measured using assigned performance indicators [15]. In the EGAD Project, Queen's university proposed a GA Assessment Summary [4]. Similarly, a procedure to measure indicators of graduate attributes is proposed by McMaster University [9]. In 2012, Concordia University, Dalhousie University, Queen's University, University of British Columbia, University of Calgary and University of Manitoba also reported that they were implementing faculty-wide indicator development approach [8]. The Graduate Attribute Committee at University of Toronto developed their own faculty level outcomes and indicators [14] while allowing for modification of performance indicators at the departmental level [8]. In 2014, Guelph presented their own faculty process [3] defining indicators for each GA. McGill University in preparation for their 2016 accreditation for 10 of 11 engineering programs determined the graduate attribute indicators for each component within a graded assessment tool $[10,11]$.

\subsection{The Problem}

CEAB mandates a common set of 12 graduate attributes across all engineering programs. However, each program within a faculty has its own set of performance indicators. This is problematic when trying to implement a consistent reporting framework at the faculty level. GAIA has been improved to support such a framework.

It is also important to ensure a common process across the faculty to meet the $\mathrm{CEAB}$ requirement for continuous improvement of engineering programs thus the faculty as unit. Tool support is needed to ensure a consistent, documented, and scheduled faculty-wide continuous improvement process across all programs in the faculty.

\subsection{Methodology}

In approaching this problem, we performed two types of analysis - vertical (per program) and horizontal (cross faculty). Vertical analyses allow for identification of common structural levels within each program. Horizontal 
analyses oppose and compare program levels cross faculty (different programs). After comparing the findings, we were able to recognize identities (same graduate attributes), similarities (the use of similar performance indicators) and differences (program-specific learning outcomes, respectively different rubrics). We elaborate in detail on the analyses in Section 2.2.

\subsection{Significance of the Results}

Support for faculty level reporting in GAIA has resulted in a more structured and consistent approach to graduate attribute assessment across all three programs and increased the ability of the three programs to interact and leverage common elements. At the same time, the definition of a common continuous improvement process with a set of clearly defined and scheduled deliverables and associated templates, has reduced the management burden and ensured a level of consistency and completeness in the process.

\section{FACULTY LEVEL SUPPORT WITH GAIA}

Faculty level support with GAIA addresses two major CEAB accreditation requirements consistently across all programs in the faculty:

- Assess student achievement for all 12 GA with data collected to measure performance of students at different stages throughout entire program;

- Implement and document continuous improvement process based on ongoing GA assessment.

In the School of Electrical Engineering and Computer Science, a committee was tasked to implement a common Continuous Improvement Process (CIP) across all three engineering programs: electrical (ELG), computer (CEG), and software (SEG).

\subsection{Common Continuous Improvement Process}

To standardize and centralize documentation and management of data, a Graduate Attribute Folder (Fig. 1) was introduced as a mechanism for supporting and standardizing a common Continuous Improvement Process (CIP) based on consistent, scheduled deliverables defined by templates. The documents, data and templates are grouped into folders as follows:

- Faculty CIP folder contains agendas and minutes from meetings of Faculty CIP committee and relevant resources (research papers, notes on other university approaches, presentations etc.) that the committee has collected.

- Templates folder contains standardized common templates for the documents that are used within each program to document, manage, and organize
CIP: Annual Report, Annual Meeting Agenda and Minutes, and CIP task notifications templates (which are used to ensure submission of data and completion of reports within scheduled deadlines).

- Program Folders (one for each program) store the data and documents for the continuous improvement process of each program (CEG, ELG, SEG). The Common Courses folder contains the data and documents from courses that are common to all three programs

Common Continuous Improvement Process

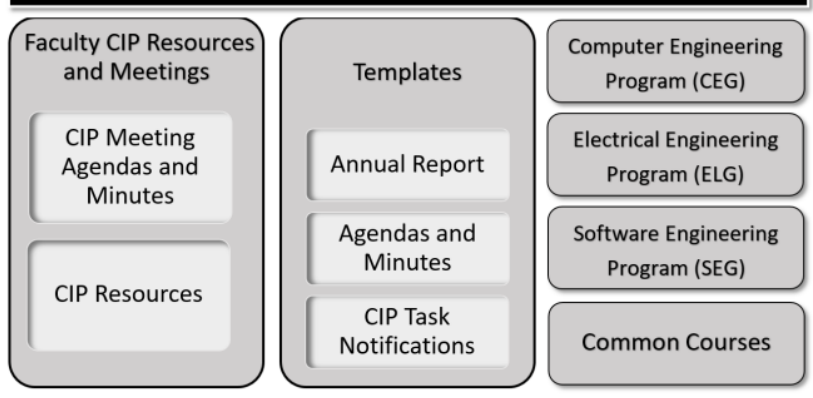

Fig. 1. GA Folder for Common CIP.

Figure 2 below, shows the organization of the program folder for software engineering. This organization is repeated and identical for all programs. There is a subfolder that manages and documents the CIP for each year since the last accreditation. In this case, the program folder contains the documentation and data from the last accreditation in 2014, and has a folder for each year since then (2014-2015, 2015-2016, 2016-2017). Eventually, there will be a subfolder for 2017-2018, 2018-2019, and 2019-2020 as the next accreditation is scheduled to take place in 2020.

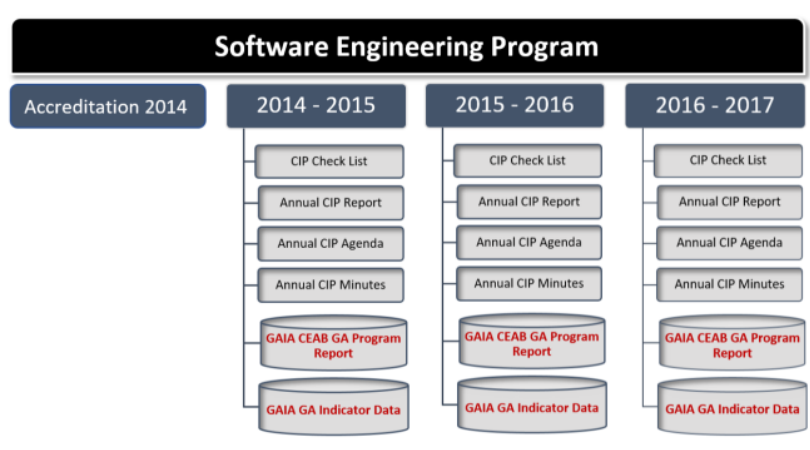

Fig. 2. SEG Program View.

Within each year, there is a CIP Checklist that is used to keep track that all steps involved in the CIP for that year have been completed, including the collection of data, creation of documents, and notifications to ensure 
completion on schedule. The key documents and data stored are:

- Annual CIP Report

- Agenda/Minutes of Annual CIP meeting

- GA Program Report

- GA Indicator Data

The annual CIP Report and Meetings are mandated and defined by the Faculty. The GA Program Report is generated by the GAIA tool based on GA Indicator data, and includes tables 3.1.1, 3.1.2, 3.1.3 and 3.1.4 as mandated by CEAB as well as additional graphs and advanced features to aid in analysis. GA Indicator Data is data collected, managed and archived by GAIA tool from program courses, COOP and other sources.

\subsection{Vertical and Horizontal Analysis}

Initially, each program had its own set of performance indicators, which was problematic when trying to achieve consistent reporting at the faculty level that could support cross-program comparisons. The vertical analysis in Figure 3 below showed each program aggregated data into three levels:

- Level I: Learning Outcomes

- Level II: Performance Indicators

- Level III: Graduate Attributes

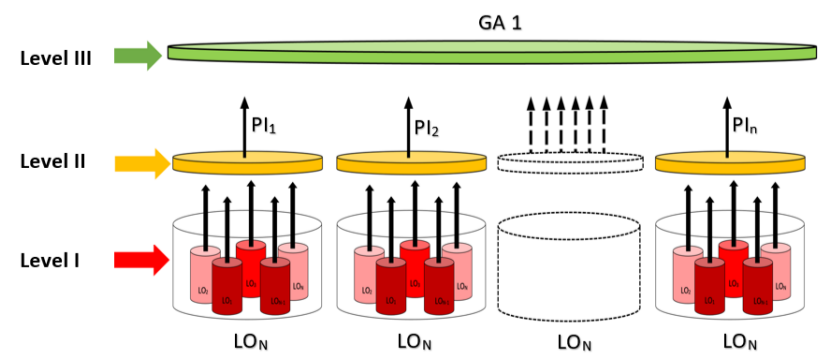

Fig. 3. Vertical analysis per graduate attribute.

At level III we have the 12 graduate attributes specified by $\mathrm{CEAB}$ for graduate attribute assessment. Each program had its own set of indicators that measured achievement for a particular graduate attribute. Those indicators were determined by the measurement of learning outcomes from particular courses. Usually, professors for individual courses were asked to determine what graduate attributes they were addressing and how they were measuring student achievement of those graduate attributes. It is not surprising that this bottom-up approach resulted in performance indicators that were not only program specific, but very course-specific at a low or detailed level of granularity.

In figure 4, we illustrate how a more top-down approach mandated by a common CIP leads to a common set of indicators that can be shared across programs. The Faculty Continuous Improvement Process mandated a common program report that would chart a common set of indicators across the 12 graduate attributes. The data for those indicators were obtained from measuring student achievement on the same learning outcomes shown in figure 3 , but those learning outcomes were compiled into the common set of high-level indicators specified in the Program Reports, rather than the program-specific lowlevel indicators proposed by course professors.

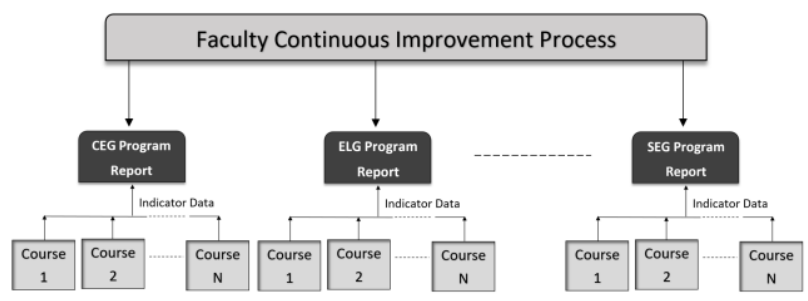

Fig. 4. Faculty Continuous Improvement Process.

This is shown in more detail in figure 5. Achievement is assessed in learning outcomes based on Rubric at the course level. These are compiled into performance indicators at the program level that report GA achievement to meet accreditation. The compilation into indicators is mandated in a standardized fashion by the faculty to ensure that achievement is reported in a consistent fashion within a standardized process of continuous improvement. The mapping of learning outcomes to program level indicators is determined by each program on its own.

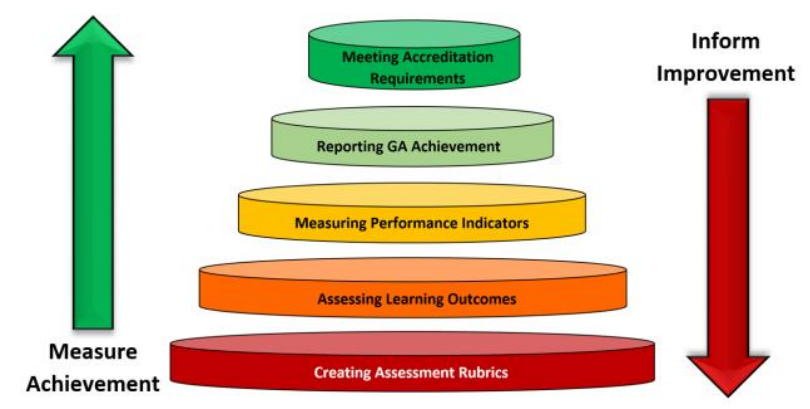

Fig. 5. Use of vertical analysis for reporting.

Within this framework, horizontal analysis provides comparison across as shown on Figure 6 for two programs - Program A and Program B. Program A has indicators IA $_{\mathrm{i}}$, where $1 \leq i \leq 7$ and Program $\mathrm{B}$ has indicators $\mathrm{IB}_{\mathrm{k}}$, where $k$ is within the boundaries $1 \leq k \leq 7$. Both programs are compared against the same graduate attribute (GA). Figure 6a shows the initial stage, where each program uses different indicators. By clustering similar indicators into identical (common) groups within 
each program (Fig. 6b) measurements are performed once and populated by GAIA respectively (Fig. 6c).

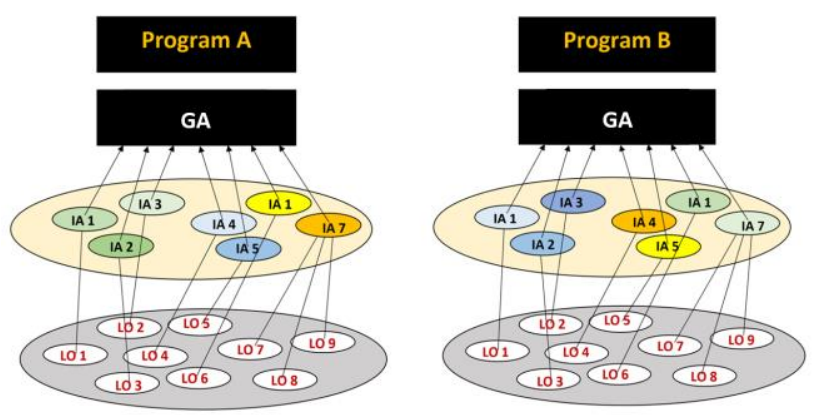

Fig. 6a. Horizontal analysis initial stage.

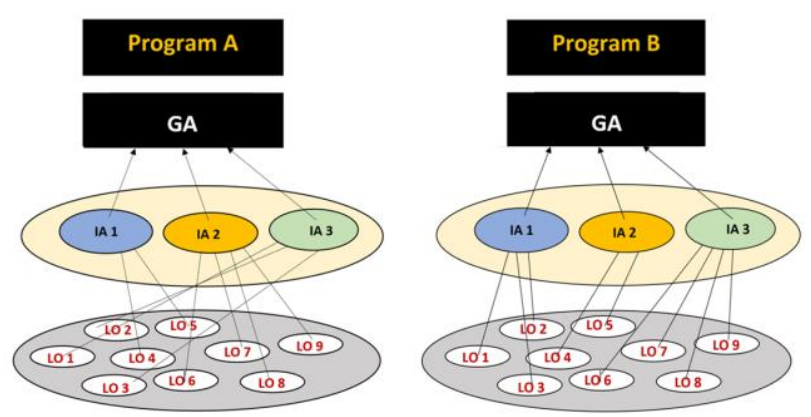

Fig. 6b. Identifying common indicators.

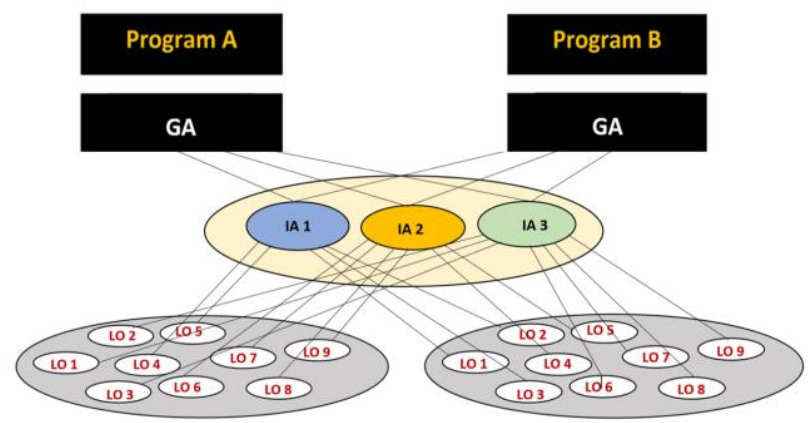

Fig. 6c. Horizontal analysis final stage.

\subsection{Common Set of Indicators (CSI)}

In addition, to horizontal analysis across all 3 programs at uOttawa, we analyzed the 12 graduate attributes defined by CEAB [1] to determine what generic indicators for the graduate attributes would be appropriate, and we studied and compared common sets of indicators that had been defined at other universities as identified in section 1.1 Literature Review.
As a result, we were able to transform the vast number of low-level indicators previously defined - 203 (CEG), 196 (ELG) and 72 (SEG) - into a consistent faculty level framework of 27 new common indicators. As shown in Table 1 , there were usually significantly more indicators defined for each GA, then there were courses relevant to the GA (as defined in the Curriculum Map for the program). This reflected the bottom-up course-driven approach to identifying indicators.

Table 1: Indicators Comparison - Indicators (Courses)

\begin{tabular}{|c|c|c|c|c|}
\hline \multirow{2}{*}{$\begin{array}{c}\text { Graduate } \\
\text { Attribute }\end{array}$} & \multicolumn{3}{|c|}{$\begin{array}{c}\text { Program Indicators } \\
\text { (Courses) }\end{array}$} & $\begin{array}{c}\text { New } \\
\text { Common } \\
\text { Indicators }\end{array}$ \\
\cline { 2 - 5 } & CEG & ELG & SEG & 4 \\
\hline \hline GA 1 & $25(6)$ & $23(15)$ & $11(9)$ & 4 \\
\hline GA 2 & $21(7)$ & $21(15)$ & $8(7)$ & 2 \\
\hline GA 3 & $16(7)$ & $16(14)$ & $7(7)$ & 2 \\
\hline GA 4 & $24(8)$ & $19(14)$ & $12(7)$ & 3 \\
\hline GA 5 & $23(8)$ & $24(13)$ & $7(7)$ & 2 \\
\hline GA 6 & $14(6)$ & $15(10)$ & $2(12)$ & 2 \\
\hline GA 7 & $19(5)$ & $17(12)$ & $7(10)$ & 2 \\
\hline GA 8 & $14(4)$ & $14(8)$ & $7(7)$ & 2 \\
\hline GA 9 & $12(3)$ & $12(9)$ & $2(4)$ & 2 \\
\hline GA 10 & $9(2)$ & $9(8)$ & $1(4)$ & 2 \\
\hline GA 11 & $12(3)$ & $12(8)$ & $4(6)$ & 2 \\
\hline GA 12 & $14(2)$ & $14(6)$ & $4(7)$ & 2 \\
\hline
\end{tabular}

We found that the three programs identified indicators working bottom-up as discussed for Fig. 3. This led to tracking course-based learning outcomes rather than program-level performance. At faculty level, we did topdown analyses as discussed for Fig. 4. As a result, there was a much smaller number of new common indicators, and typically there would be at least 3 courses measuring the indicator based on whether the treatment of the graduate attribute was introductory, applied or advanced.

The 27 common indicators are listed in Table 2 below. We considered the official CEAB description per graduate attribute and $\mathrm{CEAB}$ accreditation requirements for number of academic units [1]. Thus, the four indicators related to GA1 (Knowledge Base) match accreditation requirements for AUs. And the indicators GA 6, 7, 9, 10, and 11 are a straight forward separation of the two aspects inherent in the description of the graduate attribute. For example, GA 11 has Program Management and Economics. The dual importance of theoretical analysis and practical experience in engineering is reflected in the dual aspects of GA 2, 3, 4, 5, 8, and 12. Finally, GA 4 (Design) has the extra aspect of safety and standards which is fundamental to engineering as a profession. 
Table 2: New Common Indicators framework.

\begin{tabular}{|c|c|}
\hline GA & $\begin{array}{l}\text { New Common Indicators } \\
\text { Description }\end{array}$ \\
\hline $\begin{array}{c}\text { GA } 1 \\
\text { Knowledge base }\end{array}$ & $\begin{array}{l}\text { a) Math } \\
\text { b) Science } \\
\text { c) Other Engineering } \\
\text { d) Program-Specific Engineering }\end{array}$ \\
\hline $\begin{array}{l}\text { GA } 2 \\
\text { Problem } \\
\text { Analysis }\end{array}$ & $\begin{array}{l}\text { a) Apply Techniques } \\
\text { b) Model Formulation }\end{array}$ \\
\hline $\begin{array}{c}\text { GA } 3 \\
\text { Investigation }\end{array}$ & $\begin{array}{l}\text { a) Simulation and Prototypes } \\
\text { b) Requirements and Risk Assessment }\end{array}$ \\
\hline $\begin{array}{l}\text { GA } 4 \\
\text { Design }\end{array}$ & $\begin{array}{l}\text { a) Design Principles and Process } \\
\text { b) Open-Ended Design Projects } \\
\text { c) Standards and Safety Compliance }\end{array}$ \\
\hline $\begin{array}{c}\text { GA } 5 \\
\text { Use of } \\
\text { engineering tools } \\
\end{array}$ & $\begin{array}{l}\text { a) Selection and Use } \\
\text { b) Adapt and Extend }\end{array}$ \\
\hline $\begin{array}{c}\text { GA } 6 \\
\text { Individual and } \\
\text { team work } \\
\end{array}$ & $\begin{array}{l}\text { a) Ability to work individually } \\
\text { b) Ability to work in a group }\end{array}$ \\
\hline $\begin{array}{c}\text { GA } 7 \\
\text { Communication } \\
\text { skills } \\
\end{array}$ & $\begin{array}{l}\text { a) Written } \\
\text { b) Verbal }\end{array}$ \\
\hline $\begin{array}{c}\text { GA } 8 \\
\text { Professionalism } \\
\end{array}$ & $\begin{array}{l}\text { a) Licensing and Legal } \\
\text { b) Client Experience and Work Ethic }\end{array}$ \\
\hline $\begin{array}{c}\text { GA } 9 \\
\text { Society and } \\
\text { environment } \\
\end{array}$ & $\begin{array}{l}\text { a) Engineering Effects and History } \\
\text { b) Triple Bottom Line Sustainability }\end{array}$ \\
\hline $\begin{array}{c}\text { GA } 10 \\
\text { Ethics and equity }\end{array}$ & $\begin{array}{l}\text { a) Ethics } \\
\text { b) Equity }\end{array}$ \\
\hline $\begin{array}{l}\text { GA } 11 \\
\text { Economics and } \\
\text { project mgmt. }\end{array}$ & $\begin{array}{l}\text { a) Economics } \\
\text { b) Project Management }\end{array}$ \\
\hline $\begin{array}{l}\text { GA } 12 \\
\text { Life-long } \\
\text { learning }\end{array}$ & $\begin{array}{l}\text { a) Research and Resources } \\
\text { b) Self-directed }\end{array}$ \\
\hline
\end{tabular}

To better illustrate our approach, we use an example that shows how GA 5 is treated for the three programs Computer (CEG), Electrical (ELG) and Software (SEG) engineering. The NCI (New Common Indicators) column in Fig.7 shows an indicator map for GA 5: Use of engineering tools. As displayed in the figure, assessment of LOs will be used to measure the two new indicators $5 \mathrm{a}$ (selection and use) and 5b (adapt and extend). The map for ELG program also disclose two indicators, which do not belong to GA $5-3 \mathrm{a}$ and $2 \mathrm{~b}$ (highlighted in yellow in the figure). During the analysis, it was identified that they map the old 5.A-11 and 5.C-6 ELG indicators onto the new common indicators related to GA 3 and GA 2 respectively. In GAIA, they will be used when creating reports on their corresponding GA.

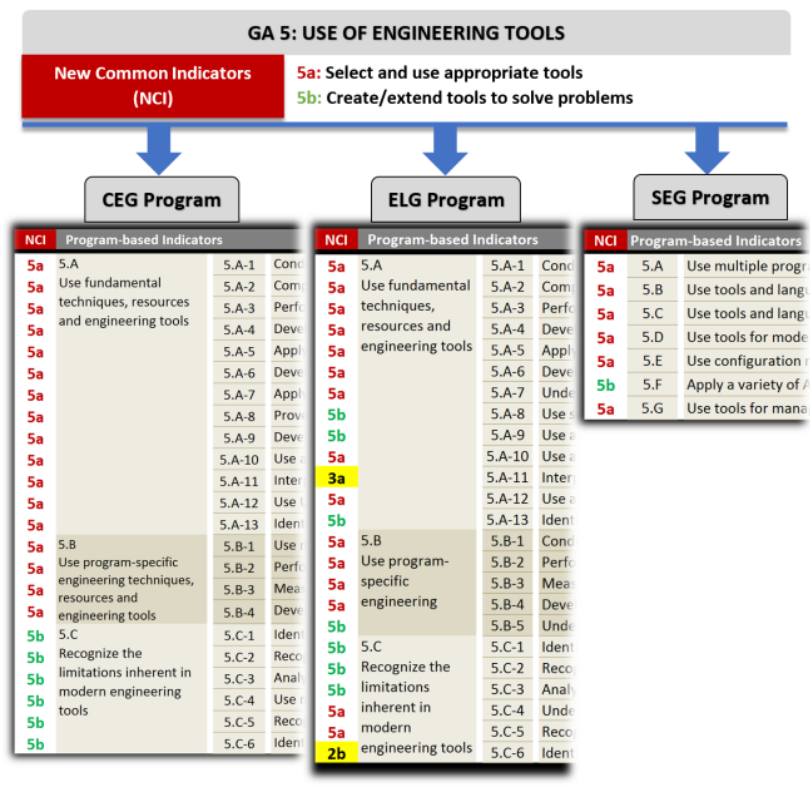

Fig. 7. Indicator map for GA 5.

\section{RESULTS AND DISCUSSION}

We focused on the difference between low-level detailed indicators driven by course learning outcomes and high level generic indicators driven by a common continuous improvement process at the program level. An analysis of the curriculum maps for each program indicated that the original low-level indicators were more numerous than the number of courses relevant to each graduate attribute. Using fewer high-level indicators allowed us to more easily compare how successful each program is at addressing the different aspects of GAs. From there we are still able to drill into courses and learning outcomes to inform program improvement.

We have also done an analysis comparing our common set of indicators against what has been developed at other universities.

In 2012, University of Toronto outlined in a memorandum regarding faculty level graduate attributes a "three-step approach to the development of the attributes" [14] involving 1)developing between 2 and 4 common for 9 programs "global outcomes" [14] per each GA; 2)identifying KPI per global outcome; 3)creating subset of indicators to measure global outcomes. The structure is very close to the initial indicator framework implemented by our CEG and ELG programs. Major difference is that our KPI groups consist of 3 to 6 KPIs (see Table 3) and although common for the two programs, they are not common across the faculty.

McMaster reinforces a "triple bottom line" for reflecting sustainability dimensions - social, economic and environmental [13], an approach we have also implemented for measuring indicators 9a and 9b (GA $9-$ 
Impact of engineering on society and environment, Table 4). We recognized the two aspects (theory vs practice) for investigation, design and problem analysis and added the additional element of standards when measuring design. The other "soft" skills have two aspects to them which we also split out (program management and engineering economics, ethics and equity, impact and sustainability).

After GACIP 2016 summit in Toronto several universities shared their approaches in developing common indicators. This allowed for additional comparison in terms of total number of indicators per program and average number of indicators per GA. Respective data from McGill [12], ÉTS [6], University of Alberta*, University of Guelph* and McMaster [13] is summarized in Table 5. (Data used in the table for University of Alberta and University of Guelph was provided to participants in the GACIP Summit, December 2016 in Toronto by Estelle Olivia-Fisher, estelle.olivafisher@ecf.utoronto.ca).

Table 5: Number of indicators for selected universities.

\begin{tabular}{|c|c|c|c|c|c|c|}
\hline \multirow[b]{2}{*}{$\begin{array}{l}\text { Graduate } \\
\text { Attribute }\end{array}$} & \multicolumn{6}{|c|}{ University } \\
\hline & $\underset{\bar{J}}{\overline{0} \Xi}$ & $\frac{\sigma}{\infty}$ & 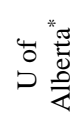 & 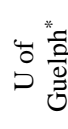 & 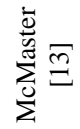 & $\begin{array}{l}4 \\
0 \\
0 \\
0\end{array}$ \\
\hline GA 1 & 8 & 3 & 14 & 4 & 5 & 4 \\
\hline GA 2 & 4 & 4 & 8 & 5 & 6 & 2 \\
\hline GA 3 & 4 & 3 & 6 & 4 & 7 & 2 \\
\hline GA 4 & 4 & 4 & 8 & 6 & 13 & 3 \\
\hline GA 5 & 3 & 3 & 6 & 3 & 4 & 2 \\
\hline GA 6 & 4 & 4 & 7 & 2 & 6 & 2 \\
\hline GA 7 & 4 & 4 & 7 & 3 & 7 & 2 \\
\hline GA 8 & 3 & 3 & 4 & 3 & 5 & 2 \\
\hline GA 9 & 3 & 3 & 6 & 3 & 4 & 2 \\
\hline GA 10 & 4 & 4 & 6 & 3 & 4 & 2 \\
\hline GA 11 & 3 & 5 & 5 & 2 & 4 & 2 \\
\hline GA 12 & 5 & 4 & 5 & 3 & 3 & 2 \\
\hline $\begin{array}{c}\text { Average } \\
\text { number of } \\
\text { I/GA }\end{array}$ & 4.1 & 3.7 & 6.8 & 3.4 & 5.7 & 2.3 \\
\hline $\begin{array}{c}\text { Total } \\
\text { number of } \\
\text { indicators }\end{array}$ & 49 & 44 & 82 & 41 & 68 & 27 \\
\hline
\end{tabular}

\section{CONCLUSION}

Standardizing assessment and process across faculty requires tool support and templates. The use of a shared Graduate Attribute Folder for deliverables and templates reinforces collaboration and improves sustainability of the common process. The use of assessment data from common courses supports automatization of the process for GA data collection, reporting and analysis. Implementing unified indicators across faculty adds to the consistency and effectiveness of analysis and assures efficient coverage of CEAB accreditation requirements by engineering programs with a faculty. The benefit is that labor and management are simplified, the work is more efficient and the results are more consistent and complete.

\section{Acknowledgements}

The work was supported by both the Faculty of Engineering and the COOP Team at the University of Ottawa, as well as NSERC. We would especially like to thank Claude D'Amours, Emad Gad, Voicu Groza, Stephane Some and Marc-André Daoust for their partnership and support.

\section{References}

[1] CEAB, 2016 Accreditation Criteria and Procedures. Published by Engineers Canada, 2016, ISSN 1708-8054, pp.121. Online. Accessed on Jan.4, 2017 from https://engineerscanada.ca/sites/default/files/AccreditationCriteria-Procedures-2016-final.pdf

[2] Chalmers D., Teaching and Learning Quality Indicators in Australian Universities (2008). Proc. of IMHE 2008 General Conference, 8-10 September 2008, Paris, France, pp.18. Online. Accessed January 4, 2017 from http: //www.oecd.org/site/eduimhe08/41216416.pdf

[3] Donald J., Gordon K., School of Engineering, University of Guelph, Faculty Panels: Enabling Learning Outcomes Assessment, (2014). Online. Accessed on Jan. 4, 2017 from http://oucqa.ca/wp-content/uploads/2014/09/GordonDonald-9.45-10.45-Day-2-Gerrard-Room-\%E2\%80\%93Presentation-Slides.pdf

[4] EGAD Project, Graduate Attribute Assessment Summary. Posted online. Accessed on January 4, 2017 from http://egad.engineering.queensu.ca/wpcontent/documents/as sessment_2page_summary_Jan_2011.pdf

[5] Engineers Australia Accreditation Board, Accreditation Criteria Summary, Document No. S02ET, (2009), pp.10. Online. Accessed on January 4, 2017 from https://www.engineersaustralia.org.au/sites/default/files/shad o/Education/Program\%20Accreditation/AMS\%20Engineeri ng\%20Technologist/S02ET\%20Accreditation\%20Criteria\% 20Summary\%20HIGHLIGHT\%20CHANGE.pdf

[6] Qualités et compétences, ÉTS, Online. Accessed May 7, 2017 from https://www.etsmtl.ca/A-propos/Departementsservices/decanats-services/BDEPE/Qualites-et-competences

[7] George A., Lethbridge T., Peyton L., Graduate Attribute Assessment in Software Engineering Program at University of Ottawa - Continual Improvement process. Proc. Of 
CEEA16, Paper 017, Dalhousie University, June 19-22, 2016, pp.6.

[8] Kaupp J. et all, A Comparison of Institutional Approaches to CEAB Graduate Attribute Requirements (2012). Proc. of CEEA12 Conf., Winnipeg, MB; June 17-20, 2012, pp.7. Online. Accessed on Jan.4, 2016 from http://ojs. library. queensu.ca/index.php/PCEEA/article/viewFile/4642/4624

[9] Lingstone, M.F., A Proposed Measurement Procedure for Indicators of Graduate Attributes, Published online by McMaster University, Mechanical Engineering. Online. Accessed on Jan. 4, 2017 from www.eng.mcmaster.ca/ lightsm/gradatt/measurement.pptx

[10] McGill University, Graduate Attributes Assessment and Reporting, (2015). Published online by McGill University, 2015. Accessed on Jan 4, 2017 from https://www. mcgill.ca /engineering/files/engineering/dept_ga_presentation.pdf

[11] McGill University, Graduate Attributes and Indicators, Detailed/Program Specific Descriptions. Published online by McGill University. Accessed on Jan 4, 2017 from https://www.mcgill.ca/engineering/files/engineering/graduat e_attributes_and_indicators_detailed_list.pdf
[12] McGill University, Engineering Graduate Attributes, 2015-2016. Online. Accessed May 7, 2017 from http://www.mcgill.ca/engineering/files/engineering/graduate _attributes_ceab_and_indicators_short_list.pdf

[13] McMaster University, Faculty of Engineering, CEAB Graduate Attributes \& Indicators, pp.7. Online. Accessed on Jan.4, 2017 from http://www.eng.mcmaster.ca/ lightsm /gradatt/indicators.pdf

[14] Norval, G., Memorandum to Executive Committee of Faculty Council, Ut, Faculty of Applied Science and Engineering. April 11, 2012 for April 26, 2012 Faculty Council Meeting, pp.17. Online. Accessed on Jan.4, 2017 from http://www.engineering.utoronto.ca/wpcontent/blogs.dir/28/files/2015/02/Revised-UCC-Grad-AttCover2c-Rpt-26-Table_Apr-11-2012.pdf

[15] University of Alberta, A report of the Committee on the Learning Environment (CLE) Subcommittee on Attributes and Competencies, (Draft). Published online by University of Alberta, June 5, 2013, pp.22, p.17. Online. Accessed Jan.4, 2017 from

http://www.provost.ualberta.ca/en/ /media/provost/Docume nts/Information/GraduateAttributes.pdf 